\title{
Impact of valuation concepts (categories) in modern conditions on the recovery of "digital losses"
}

\author{
Sergey Leonidovich Degtyarev ${ }^{1,2} *$, Daniil Alekseevich Boyarskiy ${ }^{1}$ \\ ${ }^{1}$ Ural State Law University, Department of Civil Law, 21 Komsomolskaya Str., 620137, Yekaterinburg, Russia \\ ${ }^{2}$ Ural Law Institute of the Ministry of Internal Affairs of Russia, Department of Civil Law Disciplines, 66 Korepina Str., 620057, \\ Yekaterinburg, Russia
}

\begin{abstract}
The paper addresses some issues related to the application of evaluation categories of civil law in the consideration of disputes over the compensation for damages in the context of the "digitalization" of law. It is proposed to understand the "digital losses" as losses caused in the digital sphere, or related to violations of digital rights, which would otherwise be understood by the legislator and researchers, since this does not have any effect on the essence of the institution of compensation for damages. Anticipating criticism from legal theorists, we distinguish between the terms "concept" and "category", but due to the fact that in literature and judicial practice the "evaluation concept" and "evaluation category" are used more often as synonyms, we are forced to turn to this particular option.
\end{abstract}

\section{Introduction}

From the beginning of the 1990s of the last century, it is possible to trace the gradual transformation of the Soviet civil process with its inherent inquisitional (investigative) features into a modern "mixed" process with the prevailing principles of equality and adversarial parties. In legal science and law enforcement, perceptions of the subject matter and social nature of the civil process have also been changed. At the level of axiological and epistemological attitudes, the civil process is a form of dispute resolution not limited to the establishment of "objective truth", which was characteristic of the socialist law. Other tasks of the proceedings come to the fore, such as the protection of the rights and violated interests of citizens, the formation of a respectful attitude to the law and the court.

The dynamism of public relations leads to changes in the organizational activities of the courts. The Federal Law No. 451-FZ "On amending certain legislative acts of the Russian Federation" of 28.11.2018 introduced a number of changes into the Arbitration Procedural Code of the Russian Federation and the Code of Civil Procedure of the Russian Federation aimed at accelerating and simplifying the procedure for judicial proceedings, which was caused by the increase in the number of cases considered by courts and judges in the Russian Federation, the need to reduce the burden on the judicial system as a whole.

The changes were accompanied by some doubts from the scientific community and legal practitioners. The introduction of the Institute of Simplified Proceedings into the Civil Code of the Russian Federation, the expansion of the range of cases considered in the order of writ proceedings has narrowed the scope of application of traditional, centuries-old principles of the civil process - the principle of continuity, the principle of directness, the principle of oral proceedings, the principle of pleadings.

The "digitalization" of justice continues the trend of optimizing the civil process, providing the best way to achieve the goals and objectives of justice, including by simplifying the basic elements of the judicial process [1]. The federal target program "Development of the judicial system in Russia for 2013-2024" approved by the RF Government Decree No. 1406 of 27.12.2012 provides organizational and technical measures, such as the creation of electronic justice, introduction of analytical software, formation of electronic cases and electronic archive of lawsuits providing access for citizens to justice, high-quality and effective work of the courts. At the same time, the concept of the so-called "robot judge" is being discussed, which involves delegating the function of the court to artificial intelligence in order to resolve disputes as a machine analysis of the case materials with the prospect of making decisions on the merits of the dispute.

The presented trends pose the need to discuss the principles of the civil process, search for a balance between various forms of process optimization (including informatization) on the one hand, and evaluation categories of law that do not have formal legal content.

\section{Results and Discussion}

The civil law system, together with legal principles, includes a number of evaluation concepts (categories).

\footnotetext{
Corresponding author: ds1001@mail.ru
} 
Both principles and evaluation categories of civil law are filled with specific content through the evidentiary activities of participants in the civil process, which is regulated by the rules of the civil procedural law. Moreover, it is these evaluation concepts (categories) [2], not being in most cases legal concepts, that allow the law performing its functions in the formation and preservation of social peace and well-being for citizens and other subjects of civil circulation.

The relationship between evaluation concepts (categories) such as fairness, mindfulness, integrity, etc., and the evidentiary activities of the participants in the civil proceedings are sufficiently obvious if a nonutilitarian concept of evidentiary activity and judicial evidence is applied, which in the educational literature traditionally include only the activities of the court and other participants to establish circumstances important for the correct resolution of the case, and recall the ontological content of judicial evidence as an activity that forms new knowledge [3, 4].

The widespread use of evaluation concepts (categories) is characteristic of the institution of compensation for damages. A prerequisite for this is the universality of damages as a measure of civil liability, as well as the functionality embodied in the principle of full damages. The latter relates, at a minimum, to the notion of fairness for any injured victim and the limits of its judicial protection, hence the credibility of justice and the state as a whole. For example, taking into account Paragraph 5 of Article 393 of the Civil Code of the Russian Federation, the principle of full compensation for damages is interpreted by existing judicial practice using evaluation concepts (categories) as follows: "The amount of damages to be compensated must be established with a reasonable degree of reliability". Within the meaning of Paragraph 1 of Article 15 of the Civil Code of the Russian Federation, a claim for damages cannot be refused only on the grounds that their exact amount cannot be established. In this case, the amount of damages to be compensated is determined by the court taking into account all the circumstances of the case based on the principles of fairness and proportionality of responsibility to the violation committed (Paragraph 12 of the Decision of the Plenum of the Supreme Court of the Russian Federation No. 25 "On the application of certain provisions of section I of Part I of the first Civil Code of the Russian Federation by the courts" of 23.06.2015). Therefore another aspect of evidentiary activities to establish the evaluation concepts (categories), including at the compensation for damages, is the judicial discretion, which in many respects is formed not only with the extent of knowledge of the judge about legal reality, but is also connected with the formation of the judge's legal consciousness through upbringing, education, life experience, etc.

Digital technology is becoming an integral part of legal reality and judicial proceeding. The law will inevitably seek and will hopefully find optimal and balanced answers to the new challenges of our time, which has happened more than once in the history of jurisprudence. At the same time, we need to recall that since the time of the Ancient Rome jurisprudence, law is primarily the art of good and fair, a way of just resolution of social conflicts, being more than a set of formally defined rules of behavior in the odontologic sense. Therefore, at least at the modern level of technology, the general principles of law can hardly be comprehensively expressed in strict mathematical formulas. It is worth agreeing with the opinion of V.V. Yarkov that "Until evaluation categories are translated into machine language, for example, fairness, mindfulness, good faith, it is unlikely that the machine can replace a human judge" [5].

The "electronic judge" is significantly able to simplify the time and financial costs of resolving disputes, analyze a large array of data, has other advantages noted by various researchers. However, it seems that reducing costs cannot be an end in itself in the development of justice. The main criterion for evaluating the judicial system is to obtain fair results. Conservatism is a drawback, but also a serious dignity of law as a social regulator.

Adherence to certain traditions protects the law from hasty changes, even if they are caused by promising technological or ideological trends. In this regard, no matter how we treat the digital rights, whether we recognize the quality of the new revolutionary object of civil rights, the evaluation categories of law should remain the informal measure that will take into account the real aspirations, goals, orientation of the will of the participants in legal relations under these specific circumstances. Recognition of the digitalization of the property of the absolute measure of all things can embody utopian ideas about the social order. However, on the other hand, machine absolutization may lead to the loss of the good, human that is typical for the law.

The development of technology does not mean that everything that is time-proved and tested through judicial discretion developed the rule of law of various states, including Russia, should be forgotten and sent to the archive as a sign of the archaic era from the point of view of our descendants. Like law, the activities of the court are somewhat broader than the simple implementation of the functions of one of the branches of government. Justice is the embodiment of fairness in controversial situations. From the literature, culture, as well as some experience of the practical work of the authors, it can be seen that when citizens go to court they hope for justice there, and not expect mere "public services". Thus, the idea of the court embodies the prevailing ideas in society about justice, the ability to "find the truth".

To the greatest extent this applies to private law inextricably linked to the civil process.

The trend in the development of civil legislation is the expansion of the scope of evaluation categories, such as being reasonable, prudent, taking into account the interests of the other party, sufficiency, necessity, and highlighting the degree of reliability. The expansion of the scope of evaluation categories is due to the principles of initiative and autonomy of the will of participants in property relations, which gives rise to new forms of social interaction and poses the need to take into account various individual factors and circumstances that affect 
the behavior of people. Evaluation categories thus expand and supplement the norms of the positive law, are important in conditions of formally identical legal relations.

As V.A. Bublik and M.N. Semyakin note, "formally dogmatic understanding and application of the norms of the civil law without taking into account important points of moral, moral character, good conscience of a person, etc., make a purely "instrumental" approach to legal regulation, which in the end really leads to the fact that formally everything is right, and in essence - a "mockery" of the meaning of the legislation, its main principles, its purpose" [5]. A.T. Bonner similarly said: "The establishment of the truth, the correct resolution of court cases is often impossible without a correct social and moral evaluation of actual circumstances. Moreover, this happens not only in situations where the norms of law refer to the norms of morality, but also in many other cases" [6]. First of all, the margin of appreciation in cases of the compensation for damages for improper performance of an obligation is exercised when deciding on the very fact of concluding a contract.

As R. Savatier rightly points out, "in reality, the conclusion of a contract is often much more difficult than the proposal and acceptance of a proposal. The proposal and the counter-proposal of the parties are crossed in such a way that an agreement is reached only at the end of the discussion. As a result it creates a set of corresponding conditions that make up the detailed integer" [7]. Like ebb and flow, negotiations go through various stages, return to the original positions, and end with the conclusion of a contract without an express offer and acceptance. It is appropriate to note that precontractual liability in the form of compensation for damages in itself, regardless of the conclusion of the contract, rests on the application of evaluation categories that are new to the Russian law, the boundaries of which are sought by science and practice. In addition to proving the traditional corpus delicti, the court should determine the "suddenness" and "unjustifiability" of the termination of negotiations, the formation of reasonable expectations in the continuation of negotiations [8].

Determining the conclusion of a contract by reaching an agreement in the required form, the Civil Code of the Russian Federation de facto allows any form of agreements by any method that allows reliably determining the person who expressed the will (Paragraph 1, Article 160 of the Civil Code of the Russian Federation). Both aspects are equally important for digital technology. Authentication of the person entering into the contract is possible by various technical means - use of passwords, sales codes, pin-codes of bank cards, etc. Meanwhile, none of the methods allows absolutely reliable identification of the person using the relevant data. In this regard, courts need to investigate whether a person who has access to identification data is actually the person to whom the data belongs. In relations involving legal entities, the question of whether the user has the authority to act on behalf of a legal entity requires further clarification. In law enforcement practice, the issue is resolved through the recognition of the authority of the user performing authentication, which is apparent from the situation. This, in turn, also requires an evaluation - whether the authority was formed, whether the counterparty had confidence in the validity of authority.

Equally important is the identification of a person's intention - whether he wishes to be bound by a contract or has the intention to initiate or continue preliminary negotiations. For this purpose, an analysis of the circumstances individual in each case is required, in particular, whether the person is a representative or is only authorized to negotiate, without being a representative; the extent to which the proposal for the terms of the contract is specified; whether the expression of will has the characteristics of an offer or acceptance, or is another legal fact.

According to traditional views, law deals with phenomena of the outside world, i.e. the will of one person expressed and addressed to another person. However, on the other hand, the divergence of will and expression of will leads to divergence for the purposes of the parties regarding the contract, therefore, to the invalidity and non-conclusion of the contract. In this regard, in addition to the exclusively objective factors (the content of the expression of will) reflected in the evidence, the court should take into account the orientation of the will of the parties for the presence of defects.

It seems that it is possible to fully explore the content of the processes for the formation of will when exercising the discretion of a human judge with a certain wisdom and everyday experience, an idea of unwritten rules of business cooperation. When establishing, fulfilling the obligation and after its termination, the parties are obliged to act in good faith, taking into account the rights and legitimate interests of each other, mutually providing the necessary assistance to achieve the purpose of the obligation, as well as providing each other with the necessary information (Paragraph 3, Article 307 of the Civil Code of the Russian Federation).

The need for business cooperation enshrined in this norm is an evaluation category. Providing the necessary assistance goes beyond the rights and obligations defined by the parties. Assistance consists in providing the other party with such assistance in the performance of obligations, which does not directly derive from the content of the obligation and does not lead to a violation of the other party's interests. In other words, assistance limits the beginnings of "selfishness" in private law, leaving priority to pursuing one's reasonably understood interests.

Assessment of the degree of assistance requires research into unformalized and unrecorded factors, namely, whether known actions are necessary to achieve the objective of the obligation, or whether actions are desirable, but without them it is possible to achieve the objective. At the same time, the degree of assistance seems to be different for different types of contracts. If within the purchase and sale contract the seller wishes to obtain the most profitable value of the property limiting himself to the market value of such property, then in contracts for the provision of various types of consulting services, the contractor must fulfill the order in the best 
and most profitable way for the customer, since for this purpose the customer addresses the contractor as a specialist in a certain matter. Finding the degree of assistance requires a balance between purely private interests protected by the freedom of contract and the interests of the community of persons bound by one obligation.

An example of the latter is found in judicial practice: "the principle of freedom of contract combined with the principle of good conduct ... does not exclude the obligation of the court to evaluate the terms of a particular contract from the point of view of their validity and fairness, given that the terms of the loan agreement, on the one hand, should not be clearly burdensome for the borrower, and on the other hand, they should take into account the interests of the creditor..." (Judicial Board for Civil Cases of the Supreme Court of the Russian Federation No. 25-KG1812 dated 22.01.2019).

When deciding on the amount of damages, the court should evaluate the amount of losses with a reasonable degree of reliability, take measures to minimize the amount of losses by the guilty and injured party. This takes into account the nature of sanctions in civil law, which are restorative, compensatory in nature: the purpose of compensation is to compensate for the actual adverse consequences of the violation, to restore the property position of the injured party, and not to punish the guilty party (Decision of the Intellectual Property Court No. S01-222/2020 of 12.03.2020 in case No. A40133942/2019).

In order to assess the actions of the parties to the legal relationship as reasonable, a number of factors should be taken into account that cannot be determined on the basis of a predetermined algorithm, in particular, the degree of professionalism of a debtor and a creditor, probable actions in a similar situation of an abstract legitimate participant in legal relations and what actions are usually performed by other persons to prevent the amount of losses.

There are certain strict rules in economic science regarding the theory of the rational choice, which allow modeling and conducting a mathematical assessment of the actions of economic agents (participants in property relations). However, researchers note the disadvantages of such theories. Indeed, one can imagine and give scientifically sound views on the behavior of an absolutely rational subject in a wide variety of situations. The leitmotif of actions is reaping the benefit, i.e. all that brings profit (within the limits of the law), which is considered rational.

However, the same theories distinguish the problem of limited rationality, fixing the very "human" qualities, the knowledge of which from the position of an automated algorithm is difficult. It therefore seems excessive to identify rationality as a category of behavioral economics with the rationality of participation in civil law relations. Such an approach will impute the highest degree of professionalism to persons and the calculation in all legal relations in which they enter. Rationality determined regarding the behavior of the "respectable head of the family" is somewhat wider than the model of an absolutely rational and never mistaken subject. In other words, rationality does not take into account the maximum effectiveness to prevent losses, but an average participant in legal relations with his weaknesses and merits.

The category of justice includes the historically developed social ideas of the compliance of distributions of damages, losses between the participants in legal relations to the parameters of responsibility of the offender [9]. Despite various concepts, it seems clear that justice belonged to the highest human values, and in the field of jurisprudence it is one of the basic principles of law.

There is disagreement in legal science as to whether justice is a principle of civil law, or whether this category is a social factor influencing the conduct of participants in civil relations. Without entering into a discussion on this issue, one should agree with the opinion of D.I. Dedov that "justice as the essence of law is embodied in every principle of law individually and in all principles combined" [10]. From these positions there is a moral evaluation of any social phenomenon as fair or, on the contrary, unfair by correlating it with the system of values adopted in a given society at a specific historical period. Justice is not identical to the legal equality of subjects, on the contrary, based on the system of values adopted in the society, in certain situations legal inequality can be considered fair, while legal equality - unfair

Digital technologies pose new challenges in this area. As A.I. Savelyev notes regarding smart contracts and blockchain technologies, "when a party cannot influence the progress of execution, and execution operations are fully programmed, it is difficult to apply norms that imply that the party has some kind of autonomy of will and, accordingly, the ability to violate the contract or execute it in a different way from the expectations of the other party" [11]. The opinion of O.A. Papkova seems correct: "in the exercise of judicial discretion, a category of morality can be established in cases where the legislator cannot establish the exact scope of subjective rights and obligations due to his dependence on the evaluation of the morality of behavior" [11].

The implementation of the judge's discretion is also hampered by a certain lag (for quite understandable and apologetic reasons) in the procedural legislation from the development of technology. The fact that the court has examined the evidence implies the need for the court to study electronic documents, which in turn is possible through the access to the information system. Otherwise, according to their form the evidence is presented as the images of electronic documents, and, unlike the printed e-mails that have become traditional, etc. due to the features of fixing digital rights, the image of evidence (displaying in a form accessible to the court) is expressed as certain characters that do not carry any information outside the framework of the information system. In this aspect, a "robot judge" as an information system can be effective as a tool for performing bulk data analysis, but it can hardly to embody all the wealth of human experience and mind in its calculations. 


\section{Conclusion}

Thus, proving damages in the modern conditions of digitalization of society and legal space, associated with the objective need to use evaluation concepts (categories) in relation to the elements of the subject of evidence in the case (reliability of the amount of losses, causal relationship between the wrongful act of the offender and the negative material consequences caused, the usual consequences of the offense) does not allow either now or in the foreseeable future providing artificial intelligence with a final decision on this category of disputes. The introduction of digital technologies is possible taking into account the peculiarities of the content of principles and evaluation categories of both the civil process and material law governing social relations, disputes from which are submitted to the court.

\section{References}

1. K.L. Branovitsky, Law, 1, 59-70 (2018).

2. A.S. Ryasina, Current problems of Russian law, 3(52), 31-37 (2015).
3. I.V. Reshetnikova, Proof in Civil Proceedings: Study manual for undergraduates (Uright, Moscow, 2013).

4. I.V. Reshetnikova, Reflecting on judicial proceedings: Selected works (Statute, Moscow, 2019).

5. A.I. Babkin, Lawyer, 9, 4-11 (2019).

6. V.A. Bublik, M.N. Semyakin, Bulletin of Perm University. Legal sciences, 4, 705-737 (2020).

7. A.T. Bonner, Establishing the circumstances of civil cases (Gorodets, Moscow, 2000).

8. R. Savatier, Theory of Obligations (Progress, Moscow, 1972).

9. S.L. Degtyarev, D.A. Boyarsky, Arbitration and Civil Proceedings, 8, 50-54 (2016).

10. D.E. Bogdanov, Evolution of Civil Liability from a Point of View of Justice: Comparative Legal Aspect: Monograph (Prospect, Moscow, 2015).

11. D.I. Dedov, Legal Method: Scientific Essay (Volters Kluver, Moscow, 2008).

12. A.I. Savelyev, Law, 5, 94-117 (2017).

13. O.A. Papkova, Discretion of the Court (Statute, Moscow, 2005). 